OPEN ACCESS

Edited by:

Fan Tong,

Lawrence Berkeley National

Laboratory, United States

Reviewed by:

Bo Zhang,

China University of Mining and Technology, Beijing, China

Yuwei Qin,

University of California, Berkeley,

United States

*Correspondence:

Xu Tang

tangxu@cup.edu.cn

Specialty section:

This article was submitted to Sustainable Energy Systems and Policies,

a section of the journal

Frontiers in Energy Research

Received: 11 November 2020

Accepted: 26 February 2021

Published: 24 March 2021

Citation:

Wang S, Tang $X$, Zhang $B$ and Wang W (2021) Accounting and Management of Natural Resource Consumption Based on Input-Output Method: A Global Bibliometric

Analysis.

Front. Energy Res. 9:628321. doi: 10.3389/fenrg.2021.628321

\section{Accounting and Management of Natural Resource Consumption Based on Input-Output Method: A Global Bibliometric Analysis}

\author{
Siyun Wang ${ }^{1}$, Xu Tang ${ }^{1,2 *}$, Baosheng Zhang ${ }^{1}$ and Wenhuan Wang ${ }^{3}$ \\ ${ }^{1}$ School of Economics and Management, China University of Petroleum-Beijing, Beijing, China, ${ }^{2}$ Research Center \\ for China's Oil and Gas Industry Development, China University of Petroleum-Beijing, Beijing, China, ${ }^{3}$ School of Public \\ Administration, Zhejiang University of Technology, Hangzhou, China
}

Resources and environment management have always been a research hotspot. In the context of sustainable development and environmental governance, scholars and policy makers have been increasing their research efforts on natural resource utilization and its environmental impact. By using the Web of Science Core Collection database, this article applies the bibliometric method to accomplish a systematic review about studies on accounting and management of natural resource consumption based on input-output method. The results indicate that both in terms of the quantity and quality of academic achievements and international cooperation, China is in high academic position and has made great contributions to the development in this research field. While energy and water account for a large proportion of the study objects, more attention is paid on the other kinds of natural resources, such as land, metal, and ocean. International trade is an eternal hot topic in this field. With the continuous progress of the multi-regional input-output model, the importance and feasibility in the analysis of sub-national level or region in the global supply chain gradually emerged. Combining input-output model with other methods can obtain more comprehensive and accurate results for scientific decision-making. Meanwhile, the uncertainty and limitations inherent in such models clearly need further attention.

Keywords: natural resource consumption, bibliometric analysis, co-occurrence network analysis, social network analysis, input-output analysis

\section{INTRODUCTION}

Natural resources are the important material basis of social stability and economic development. In recent decades, global resource extraction has risen to about 80-90 billion tons a year. Historical trends suggest that this number could double to 190 billion tons a year by 2060 (International Resource Panel, 2019). Resource consumption has brought unprecedented harm to the ecology environment. Climate changes such as melting glaciers, water pollution and ecosystem degradation have caused widespread concern about health and sustainable development (Lenzen et al., 2012). This resource-intensive development route is causing a rethink.

In September 2015, the 193-member states of the United Nations put forward 17 Sustainable Development Goals (SDGs) at the Sustainable Development Summit, aiming at completely solving the development problems (United Nation-UN, 2015). In September 2020, President Xi announced 
China's decision to become carbon neutral by 2060 at the 75th general debate of the United Nations General Assembly (Xinhuanet.com, 2020). This is the first long-term climate goal of China to limit carbon dioxide emissions to zero. That means China is not only under pressure to transition to a low-carbon energy system, but also need to use negative emission technologies such as carbon capture utilization and storage (CCUS) (Mallapaty, 2020). However, this systemic shift has increased the demand for other types of resources, such as copper and nickel (Li et al., 2020). This low-carbon transition complicates the economic system's demand for natural resources, which in turn makes integrated management more difficult. Globalization also leads to an increasing geospatial separation of supply and demand (Wiedmann and Lenzen, 2018). Therefore, it is necessary to consider the relationship systematically and comprehensively among natural resources, economic development, and low-carbon transition.

Input-output analysis (IOA) is a top-down economic technique developed by Leontief in the 1930s. It uses departmental currency transaction data to explain the complex interdependencies between different sectors of the economy (Leontief, 1970; Munksgaard et al., 2005). Compared with the bottom-up approach, this method can fully reflect the economic exchanges between industries without arbitrary boundaries (Suh et al., 2004; Lenzen, 2008). By calculating direct and indirect impact, Input-output method captures the environmental impacts generated over the entire supply chain from the perspective of consumer or producer. This can reflect the environmental impacts outsourcing through trade (Wiedmann and Lenzen, 2018). Therefore, the research on resource accounting and management based on Input-output method is of great significance to sustainable development. Because of the diversity of research perspective, scope and methods, the results vary greatly.

Bibliometrics is a mature literature analysis and information mining technology, which uses the law of research publication to explore the research status and development history (Van Raan, 2005). Xie et al. (2018) used bibliometric analysis to characterize the literatures related to Input-output analysis between 1990 and 2017, pointing out the most influential works and authors, and the emerging studies. Hawkins et al. (2015) surveyed the published articles regarding Environmentally Extended Inputoutput (EEIO) analysis for China in peer-reviewed journals and provided a quantitative overview of literatures. Zhong et al. (2016) reviewed research progress on natural resource accounting for the period of 1995-2014 through the methods of bibliometric analysis and social network. Previous reviews have focused on either method of Input-output or topic of resource consumption, concentrating on the patterns of these articles rather than content and conclusions. A comprehensive overview in natural resource consumption and management based on Input-output method is currently lacking. The evolution of both topic and methods needs to be further analyzed.

This systematic literature review serves to investigate this research gap by analyzing the research evolution of natural resource consumption and management based on Input-output method. It cannot only have a grasp of this field in terms of structure, but also provide empirical evidence and theoretical support for the recent resource management policies in terms of content. The rest of the article is structured as follows. Bibliometric analysis method and data are described in Part 2. An in-depth review of the patterns in this field is given in Part 3. Part 4 presents the discussion, while the conclusion drawn from the study is provided in Part 5.

\section{DATA AND METHODOLOGY}

\section{Methodology}

Bibliometric analysis is a quantitative analysis method using various external characteristics of academic publications (Van Raan, 2005). Based on statistical and mathematical methods, this method cannot only investigate the distribution characteristics and numerical laws of the bottom layer, but also reveal research hotspots and future trends (Du et al., 2015; Hu et al., 2015). Bibliometrics has become an important basis and component of library and information science. Meanwhile, word frequency analysis, citation analysis, and occurrence analysis have been widely used in empirical research (Hawkins et al., 2015; Zhong et al., 2016; Xie et al., 2018). Bibliographic coupling (Kessler, 1963) and co-citation analysis (Marshakova, 1973; Small, 1973) are primary methods of probing the frontiers of research by tracing their roots back several decades.

Bibliometric analysis can present the external characteristics of academic achievements in the form of a knowledge graph. According to different purposes, the items are selected from the literature data as nodes on the knowledge graph, and the links between the items are shown as edges (Van Eck and Waltman, 2014). In this paper, VOSviewer is selected as the visualization software of the knowledge graph. In this software, items and links' properties are described by the node weight and edge weight, called weights and strength, respectively. By calculation, items are grouped into different clusters, shown in the same color. In general, the closer the items are, the more relevant they are.

In the co-authorship analysis, the links between nations, institutions or authors represent the cooperative relationship, while the link strength stands for the number of collaborative publications. In co-citation analysis, the links between journals or publications appear as the citation of the same literature, and the link strength means the number of common citations. Links between publications in bibliographic coupling analysis act for the sharing of one or more citations, and link strength symbolizes the number of shared references for both publications. In cooccurrence analysis, the links between keywords denote the cooccurrence of the keywords, and the link strength illustrates the number of publications in which the keywords appear simultaneously (Van Eck and Waltman, 2010).

\section{Data Source}

The aim of this article is to review the literatures of natural resource consumption and management based on Input-output method. Referring to the retrieval methods of existing articles, the search criteria include three parts: resource type, Inputoutput, and usage (Jin et al., 2019). The retrieval formula is 
[Topic $=($ "Input Output Analysis" OR "Input Output Model" OR “Input Output Table” OR "Input Output Method” OR “Input Output Framework" OR "IO analysis” OR "IO Model” OR “IO table" OR "IO technique*” OR "IO framework" OR "IO method") AND Topic $=$ ("fossil fuel*" OR "natural gas" OR coal OR oil OR energy OR water OR freshwater OR wastewater OR land OR wood OR biomass OR metal OR mineral OR material OR "natural resource") AND Topic = (footprint OR use OR consumption OR withdrawal OR demand OR requirement OR extraction)]. A total of 1,977 peer-reviewed articles in English from 2000 to 2020 (as of July 9, 2020) were retrieved from the Web of Science Core Collection (SCI-Expanded, CPCI-S, CCRExpanded, IC.). Articles that are not within the scope of this study are excluded, such as those applied in control systems, inventory management, biochemistry, computer science, oncology, etc. Therefore, after data cleaning, 1,824 references were finally determined. Each document contains information such as title, author, organization, abstract, keywords, and citations.

Citation analysis is used to study the contributions of countries, institutions, and authors and their ways of cooperation. And the most influential authors, articles, and mainstream journals in this field are explored by this method. Keyword's co-occurrence and bibliographic coupling analysis are used to study the topic cluster composition and hot topics.

\section{RESULTS}

\section{The Performances of Publications}

It can be seen from Figure $\mathbf{1}$ that the distribution and variation trend of 1,824 articles can be roughly divided into three stages. There is an increase of papers published per year from two articles in 2000 to 17 articles in 2004, with an average increase of 3.75 papers per year. From 2005 to 2014, the annual publication fluctuated from 27 articles in 2005 to 103 articles in 2014, with an

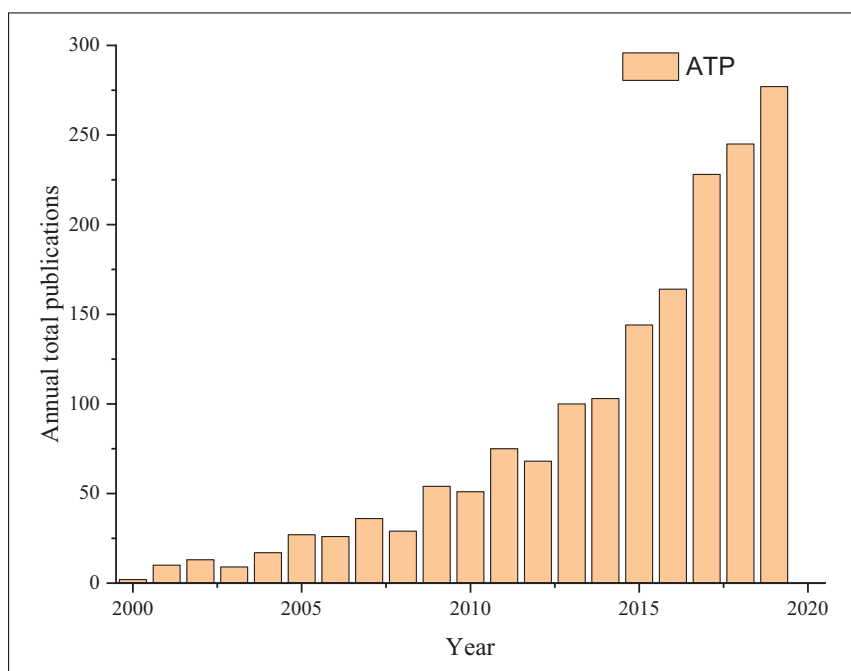

FIGURE 1 | The number of publications in this field from 2000 to 2019 . ATP is the annual total publication. average yearly increase of 8.44 . Since 2015 , the annual publication has multiplied to 277 articles in 2019, representing an average increase of 33.25 articles per annum.

This is roughly in sync with the formulation of the global climate-change governance system and SDGs. On June 4, 1992, the United Nations Framework Convention on Climate Change (UNFCCC) and the Convention on Biological Diversity (CBD) were adopted in Rio de Janeiro, Brazil. After that, countries began the practical exploration of market-based climate governance. However, due to the shortcomings of market mechanisms such as carbon trading, carbon compensation and carbon tax, negative externalities of the environment caused new economic inequality, ecosystem degradation, and human rights problems in the thirdworld countries (Xie et al., 2014). In the 21st century, the rapidly developing third-world countries have realized the importance of ecology, environment, resources, and sustainable development. In 2005, 142 countries and regions signed the Kyoto Protocol, which identified the central issue of Burden Sharing. In addition, a joint commitment to reduce greenhouse-gas emissions by 2020 is made (Kyoto Protocol, 2005). In September 2015, the member states of the United Nations proposed 17 SDGs, aiming at solving the development problems in the three dimensions of social, economy and environment, and shifting to the path to sustainable development. In December of that year, the Paris Agreement was approved to further incentive each country to make more efforts to reduce emissions through Opportunity Sharing. These milestones bear witness to academic progress within the field.

\section{The Contribution of Countries (regions)}

Since 2000, scholars from 68 countries have made outstanding contributions to the field over the past 20 years. Among them, an in-depth analysis on 40 countries whose publication is no less than five are carried out. A total of 222 partnerships have been formed in these 40 countries, with the results shown in Figure 2 and Table 1.

Although China (853 articles, 17,491 citations) started relatively late in this field, it has taken a global lead in the count of publication and citations, much higher than the United States (USA) (369 articles, 13,678 citations), the United Kingdom (UK) (181 articles, 7,396 citations), Japan (150 articles, 4,541 citations), and Australia (140 articles, 5,838 citations). However, Singapore (21 articles, 1,478 citations) and Norway (84 articles, 5,024 citations) ranked high among the 40 countries with an average of 70.38 citations per article and 59.81 citations per article.

Publications by authors from different countries can be defined as international collaborative publications. The ratio of the number of international collaborative publications to the total number of publications by a country can reflect the degree of international cooperation in this country. The ratios of United Kingdom (0.66), Netherlands (0.75), Norway (0.71), Germany (0.58), and Austria (0.85) are all greater than 0.5, indicating that these countries are more likely to conduct research in the form of international cooperation. It was followed by United States (0.49) and Australia (0.46). Although China's ratio $(0.28)$ is smaller than those of any of the above countries, the total volume of collaborative publications is the highest in the world, with 235 collaborative publications. 

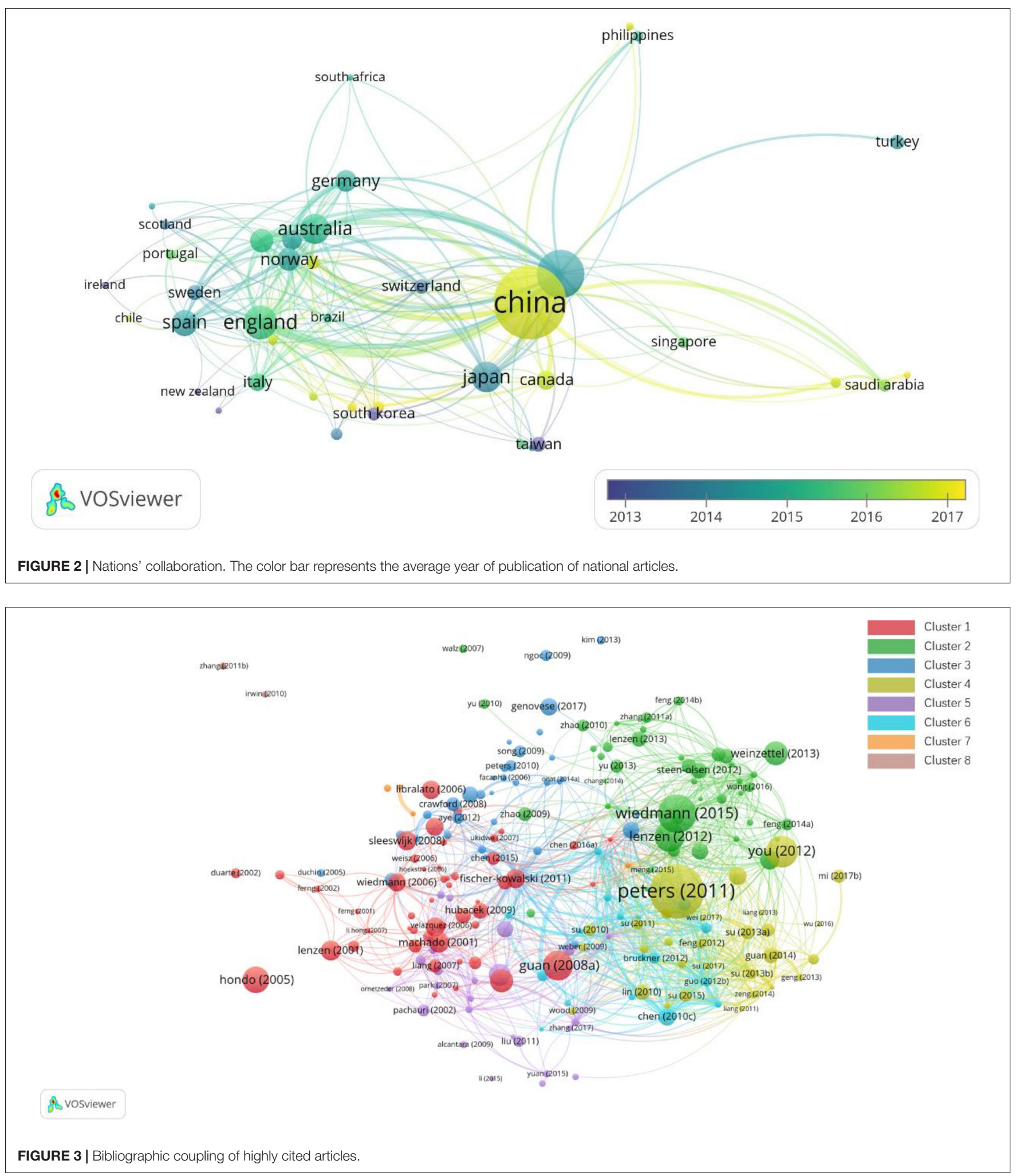

In the global cooperative relationship, China and United States have the closest cooperative relationship in this field with 124 articles published in collaboration, accounting for $69.27 \%$ of the total in United States and $52.77 \%$ in China.
The number of cooperative articles between China and United Kingdom came second, with 71 articles jointly published, accounting for $5.90 \%$ of the total, $59.66 \%$ for United Kingdom and $59.66 \%$ for China. After that, United Kingdom and 


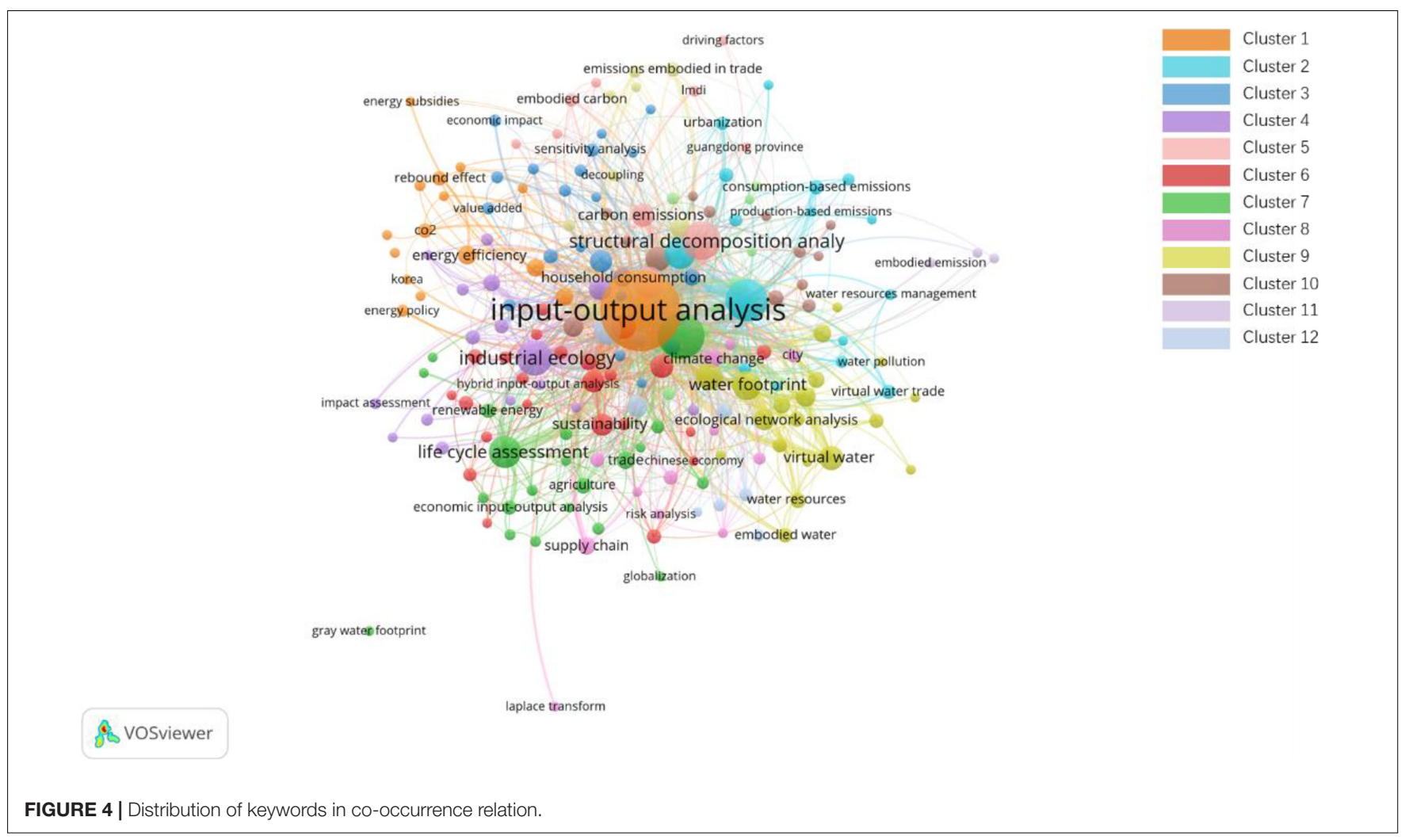

United States jointly published 47 articles, accounting for 3.91\% of the total volume of articles published by 40 countries. China has become an indispensable part of this field and is playing an important role in promoting research progress in this field. The performances of institutions and authors are shown in Supplementary Material.

\section{The Performances of Journals}

The main carriers of academic achievements are articles and journals. The 1,824 target papers are from 259 journals. Fortythree journals with no less than five publications in 20 years are analyzed in depth. The specific results are shown in Tables 2, 3.

There are $79.89 \%$ of the total papers in this field published in 15 journals as shown in Table 2 . And the citations of these papers account for $87.80 \%$ of the total. The distribution of high-level achievements in this field is relatively concentrated. Ecological Economics (115 articles, 6,846 citations) is the most influential journal with the most citations. Energy Policy (133 articles, 5,833 citations), Journal of Cleaner Production (290 articles and 5,490 citations), Applied Energy (115 articles, 3,822 citations), and Journal of Industrial Ecology (125 articles, 3,584 citations) followed closely. Among the 15 journals, The Global Environmental Change with the highest impact factor (10 articles, 1,261 citations) ranked 9th in terms of publication. Journals such as Environmental Science and Pollution Research (26 articles, 78 citations), Environmental Pollution (5 articles, 76 citations), Earths Future (9 articles, 84 citations), and Environmental Research Letters (18 articles, 612 citations) have published more articles in recent years. This indicates that these journals begin to pay more attention to this research field. Journal of Cleaner Production (290 articles, 5,490 citations), Science of the Total Environment (46 articles, 902 citations), and Resources Conservation and Recycling (58 articles, 647 citations) all have high publication and citation. And their year of average publication is also recent. This shows that these three journals not only have high influence, but also have been active in the academic forefront.

\section{The Characteristics of Publications}

Among 1,824 selected articles, 211 articles have been cited more than 60 times. The bibliographic coupling analysis was carried out, and the evolution path of the topic was explored. The specific results are shown in Supplementary Tables A, B.

The top 10 cited articles are mainly from countries such as Australia, Norway, and China. "Growth in Emission Transfers Via International Trade From 1990 to 2008" published in Proceedings of the national academy of the united states of America (PNAS) in 2011 has a great influence, with 655 citations (Peters et al., 2011). This paper calculates trade-related carbon emissions of 113 countries and regions between 1990 and 2008 . It was found that emission's transfers through international trade tended to exceed emission's reductions by importing countries. "The Material Footprint of Nations," also from PNAS, ranked second with a cumulative 468 citations (Wiedmann et al., 2013). This paper focuses on natural resources, including fossil energy, metal minerals, non-metallic minerals, and biomass energy. And this paper conducts a quantitative analysis of the natural resource footprint and its drivers in 186 countries in 2008 from a 


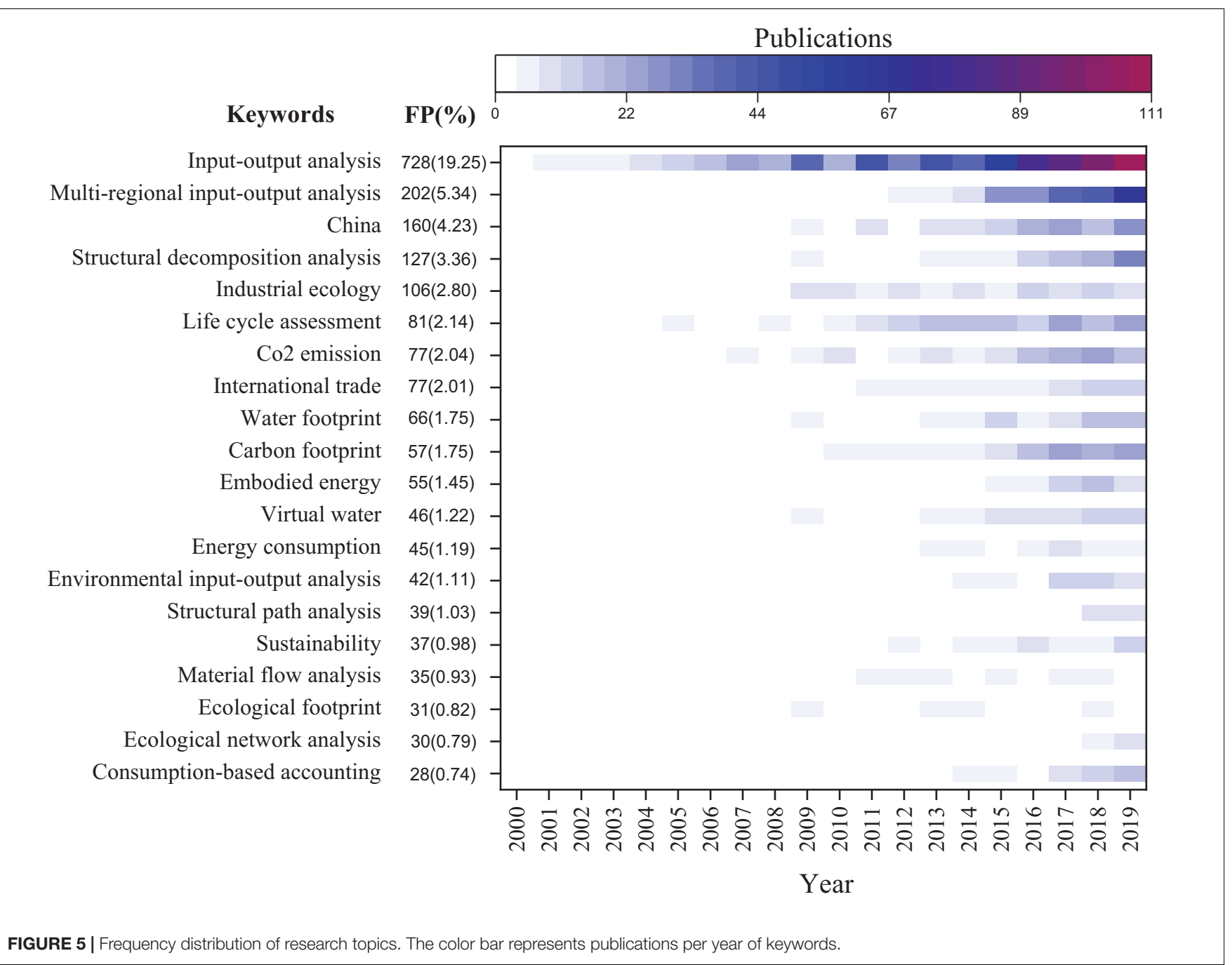

consumption-based perspective. The results show that the use of non-domestic natural resources in developed countries is about three times the volume of physical trade. A paper published in the Global Environmental Change in 2013, "Affluence Drives the Global Displacement of Land Use" ranked sixth with a cumulative 287 citations (Weinzettel et al., 2013). This paper tracks the land and ocean footprints of 113 countries in the global supply chain based on the GTAP database. It found that high-income countries require more biologically productive land per capita than lowincome countries, with a one-third increase in a country's land and ocean footprint per capita for each doubling of per capita income. The above three articles all carry out accounting analysis on natural resource consumption and transfer embodied in international trade from a global perspective, while other highly cited literatures mainly focus on a single country.

Bibliographic coupling occurs when two documents share one or more citations, indicating that the content expressed by these documents is about the same topic (Boyack and Klavans, 2010). The more references the two articles share, the more similar the content will be. According to the differences in shared citations, the 211 articles were divided into eight clusters (Figure 3).
According to the scope of research objects, eight clusters are divided into two categories. One is the research on carbon emissions from fossil fuel's consumption; The other one is the research on natural resources, including energy, water, and land.

Cluster 1, represented by Lenzen and Murray (2001); Hondo (2005), and Guan et al. (2008) calculate and analyze the energy and related carbon emissions embodied in international trade. Since then, research has evolved in two directions. One is a change of topic. Cluster 5, represented by Weber and Matthews (2008); Baiocchi et al. (2010), and Liu et al. (2011), further analyzes the impact of household consumption patterns on carbon emissions from a micro perspective. Cluster 8 and Cluster 7 study the inter-sectoral economic dependence and vulnerability to shocks among technical facilities from a macro perspective through Input-output. The other one is a shift in methodology. Cluster 3, represented by Tukker and Jansen (2006); Wiedmann et al. (2011), and Genovese et al. (2017), started to compare and analyze the carbon emission results related to energy consumption calculated by top-down Input-output method and bottom-up life cycle analysis, and built an improved integration model from various aspects. 
TABLE 1 | Top 10 countries (regions) in cumulative publication.

\begin{tabular}{|c|c|c|c|c|c|c|}
\hline Country & TP (\%) & TC (\%) & Avg. pub. year & Num. co-countries & Num. co-publication (\%) & RA \\
\hline China & 853 (31.65\%) & 17491 (21.73\%) & 2016.73 & 31 & 235 (19.53\%) & 0.28 \\
\hline United States & 369 (13.69\%) & 13678 (16.99\%) & 2014.33 & 32 & $179(14.88)$ & 0.49 \\
\hline United Kingdom & 181 (6.72\%) & 7396 (9.19\%) & 2015.44 & 26 & 119 (9.89\%) & 0.66 \\
\hline Japan & $150(5.57 \%)$ & 4541 (5.64\%) & 2014.05 & 17 & 55.5 (4.61\%) & 0.37 \\
\hline Australia & 140 (5.19\%) & 5838 (7.25\%) & 2015.08 & 19 & $64.5(5.36 \%)$ & 0.46 \\
\hline Spain & 110 (4.08\%) & 2672 (3.32\%) & 2014.40 & 21 & 39.5 (3.28\%) & 0.36 \\
\hline Netherlands & 87 (3.23\%) & 3152 (3.92\%) & 2015.34 & 22 & $65.5(5.44 \%)$ & 0.75 \\
\hline Norway & $84(3.12 \%)$ & 5024 (6.24\%) & 2014.63 & 18 & $60(4.99 \%)$ & 0.71 \\
\hline Germany & $73(2.71 \%)$ & 3050 (3.79\%) & 2014.77 & 15 & $42.5(3.53 \%)$ & 0.58 \\
\hline Austria & 67 (2.49\%) & 3179 (3.95\%) & 2014.55 & 18 & 57 (4.74\%) & 0.85 \\
\hline
\end{tabular}

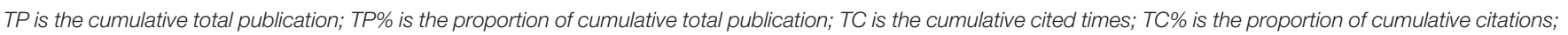

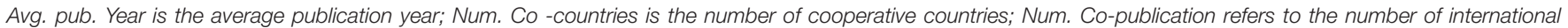
collaborative publications; RA is the ratio of the number of international collaborative publications in a country to its total number of publications, the same as below.

Around 2010, the research focuses gradually shifted from the environmental impact to other kinds of natural resources such as energy, water, land, and minerals, primarily represented by literature such as Chen and Chen (2010); Chen and Zhang (2010), and Bruckner et al. (2012). Since then, with the improvement of the Multi-regional Input-output database, the research mainly focuses on the consumption and management of natural resources in countries and even cities from the perspective of the global supply chain.

\section{The Features of Keywords}

Keywords are the epitome of the article, which can let readers understand the key content of article in a short time (Xia et al., 2017). There were 3,879 keywords in 1,824 articles. In order to increase the effectiveness of keyword analysis, this paper

TABLE 2 | Top 15 cited journals.

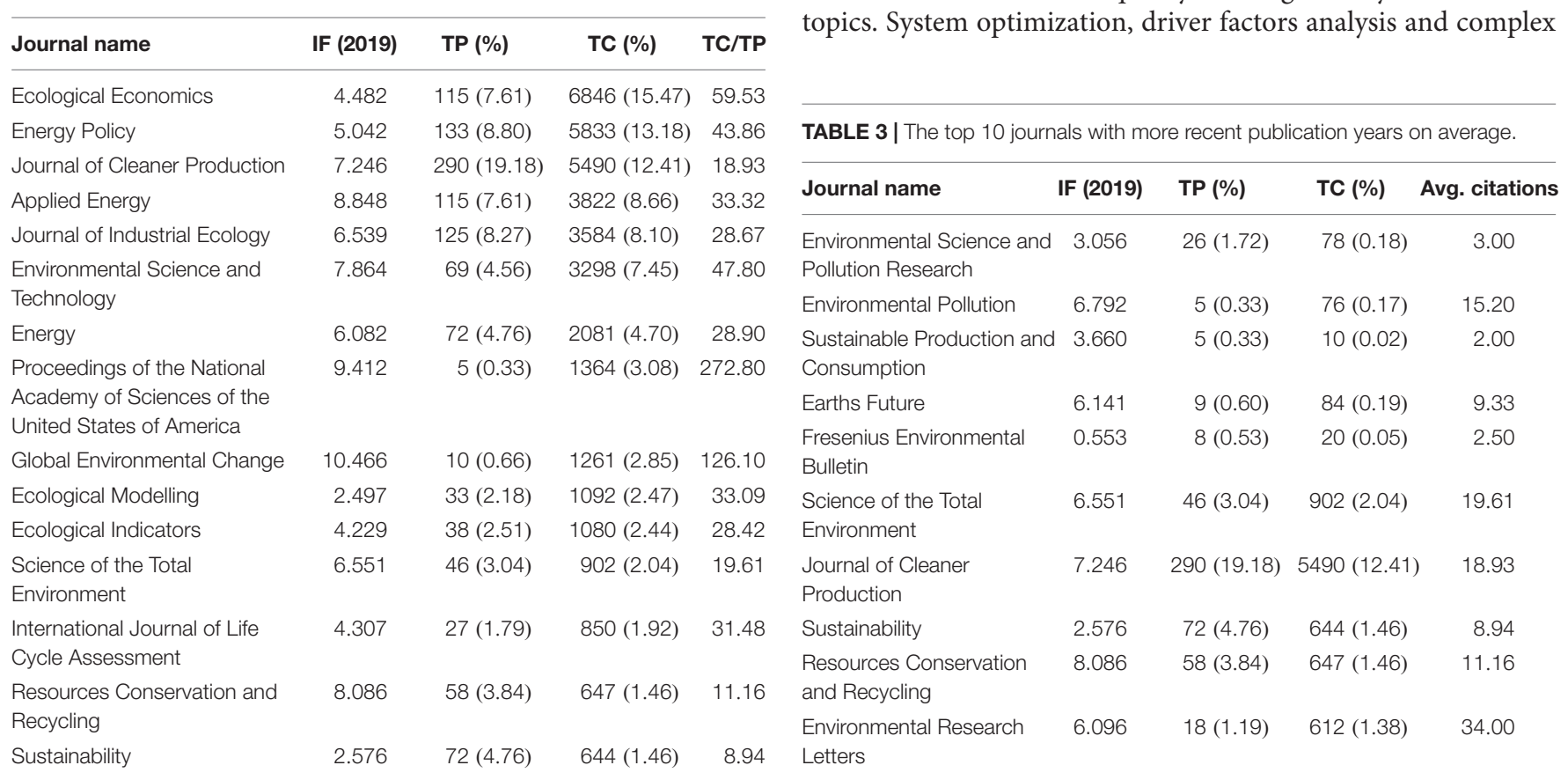

first preprocesses the original data and unifies the keywords with similar meanings into one expression form. For example, Input-output analysis is used to represent Input-output models, Input-output modeling, and other similarly keywords. After that, 195 keywords that appeared no less than five times were analyzed deeply.

From the perspective of occurrence frequency, there is no doubt that "Input-output analysis" is the keyword with the most occurrences (Figures 4, 5). "Multi-regional Input-output analysis" and "China" ranked second and third, respectively. The current research in this field has turned to the discussion of interregional issues, and the research object has been inclined to China. "Structural decomposition analysis" and "Life cycle assessment" rank fourth and sixth, respectively. It shows that many articles in this field combine the above two methods with Input-output. Table 4 shows the 20 most-recent keywords in terms of publication per annum. Energy-water nexus, energy transition and trade inequality have gradually become hot
topics. System optimization, driver factors analysis and complex

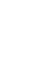


TABLE 4 | Research frontier distribution.

\begin{tabular}{|c|c|c|c|c|c|}
\hline Keywords & FP (\%) & Avg. pub. year & Keywords & FP (\%) & Avg. pub. year \\
\hline LMDI & 7 (0.19\%) & 2018.57 & Final demand & $7(0.19 \%)$ & 2018.14 \\
\hline Energy-water nexus & $10(0.26 \%)$ & 2018.40 & Construction sector & $8(0.21 \%)$ & 2018.13 \\
\hline Driving factors & $5(0.13 \%)$ & 2018.40 & Guangdong province & $6(0.16 \%)$ & 2018.00 \\
\hline Energy conservation & $5(0.13 \%)$ & 2018.40 & Optimization & $6(0.16 \%)$ & 2018.00 \\
\hline Energy transition & $5(0.13 \%)$ & 2018.40 & Production-based emissions & $6(0.16 \%)$ & 2018.00 \\
\hline $\mathrm{SO}_{2}$ emissions & $5(0.13 \%)$ & 2018.40 & Carbon footprints & $5(0.13 \%)$ & 2018.00 \\
\hline Water-energy nexus & $14(0.37 \%)$ & 2018.21 & Urban agglomeration & $7(0.19 \%)$ & 2017.86 \\
\hline Interprovincial trade & $5(0.13 \%)$ & 2018.20 & Complex network & $12(0.32 \%)$ & 2017.83 \\
\hline Linkage analysis & $5(0.13 \%)$ & 2018.20 & Consumption-based emissions & $13(0.34 \%)$ & 2017.69 \\
\hline Trade imbalance & $6(0.16 \%)$ & 2018.17 & Gray water footprint & $5(0.13 \%)$ & 2017.60 \\
\hline
\end{tabular}

networks are the new research methods in this field. However, the frequencies of occurrence and co-occurrence of the above keywords are still small, indicating that there are still large academic gaps worth studying.

Through the classification of the meanings of keywords, it is found that among 195 keywords, 48 keywords were research objects, and 57 keywords were research methods, while the remaining 92 keywords included research background and other expressions.

The object includes a single kind of resources and resource nexus. In terms of a single type of resources, the pollutants emitted by fossil energy consumption have been studied the most, among which carbon dioxide emission and sulfur dioxide emission had a larger proportion of single pollutant types. Then there is the study of primary energy and renewableenergy consumption, in which coal, electricity, and biomass energy subcategories are studied more. The next is the study of water, which gray water footprint and water pollution research more. More and more attention has been paid in the study on the consumption of land metals and other materials. The other type of research focuses on the nexus of multiple resources, which is mainly energy-water nexus, water-energy nexus, and energy-water-food nexus at present. The essential metaphor of these nexuses is the synergy between them. The implementation of single resource-saving actions in resourceintensive industries would effectively promote the synergistic other resource-conservation effects (Bleischwitz et al., 2018; Tang et al., 2018).

In terms of research methods, Input-output analysis extends and refines the model itself, such as Multi-Region Input-output model, Physical Input-output model, and other Extended Inputoutput. On the other hand, it is actively applied in combination with other models, such as hybrid life cycle analysis and economy-wide material flow analysis. In addition, structural decomposition analysis (SDA), structural path analysis (SPA), network analysis, data envelopment analysis (DEA), computable general equilibrium (CGE), and multi-objective optimization methods are also widely used in this field.

In other aspects, there are many case studies in China, Australia, South Korea, and other countries, including cities and city agglomeration. The construction industry, electric vehicle and electric power industry are also highly focused. International trade, inter-provincial trade, global supply chain, climate change, sustainable development, industrial structure reform, and energy transition are the frequent research background.

\section{DISCUSSION}

\section{Improvement of Research Method}

The uncertainty of Input-output analysis has been mentioned many times in the selected articles. First, the Input-output model itself has many uncertainties and limitations, including the process of data investigation, model coordination and balance, and the assumption of departmental homogeneity in order to maintain the stability of technical and economic links between departments (Hawkins et al., 2007; Lenzen, 2008; Weber, 2008). Secondly, the single regional Input-output model assumes that the production technologies of imported goods and services are the same as those of the economy surveyed. However, this assumption is not consistent with reality. In order to reduce the uncertainty caused by this assumption, the multi-regional Inputoutput model is built with other uncertainties, such as the sectoral division system of multiple regions, the currency exchange rate, and the treatment of other regions in the world (Weber, 2008). At the same time, Input-output tables from different scientific research institutions and databases also have different results due to different data sources and calculation methods (Hoekstra et al., 2014). So, the uncertainty and limitations inherent in such models clearly need further attention from the research community, which needs to improve the availability and quality of data. There is also a need for more in-depth evaluation of the data results and model programming estimates for each country (Wiedmann, 2009; Tukker et al., 2018).

Jumping out of the Input-output model itself, it is found that Input-output model is widely combined with others to establish an integrated model. In the process of accounting, it can be found that Input-output is often combined with life cycle analysis (LCA) or material flow analysis (MFA). Different from the top-down macroscopical characteristics of Input-output method, life cycle evaluation can provide microscopic data with the bottom-up paradigm, while material flow analysis can track the flow and stock of materials, which are complementary to Input-output method from distinct perspectives (Hertwich et al., 2000; Ayres and Ayres, 2002; Fischer-Kowalski et al., 2011; Beylot et al., 2020). Nevertheless, due to the initial "pure 
sector" hypothesis of Input-Output model, the data collected through LCA or MFA must be merged into the unified sector (Sleeswijk et al., 2008; Kondo et al., 2012; Wang et al., 2021). In the aspect of driving factor analysis, structural decomposition method (SDA) and LMDI and measurement methods are used in some researches. However, in the decomposition process, SDA will produce a non-unique problem of decomposition results, leading to great differences among the decomposition results and reducing the accuracy and reliability of the conclusions (Peters et al., 2007; Guan et al., 2008; Lenzeiy et al., 2012; Liang et al., 2013). LMDI can overcome the cross-term problem, but it cannot analyze the resource consumption effect related to trading or demand. Therefore, some articles combine SDA and LMDI to analyze the driving factors (Wang and Yang, 2015; Román-Collado and Colinet, 2018). Most researches adopt structural path analysis (SPA) and network analysis. SPA is a step-by-step path analysis method, which can decompose the effect to each production layer from the perspective of consumption along the supply chain (Hong et al., 2016). In network analysis, the connection between individuals can be expressed through the set of nodes and edges. Compared with SPA, network analysis theory can capture the information of the transmission sectors in the supply chain (Liang et al., 2017). Therefore, some articles combine SPA and network analysis methods to analyze the path of resource consumption in the supply chain (Feng et al., 2019). In the aspect of natural resource management, Input-output model is also combined with multiobjective optimization, data envelopment analysis, computable general equilibrium model and other methods to explore the integrated management mode and path (Jin et al., 2017; Tang et al., 2018). In addition, there are also literatures that combine Input-output with GIS for spatial analysis, system dynamics for dynamic simulation, etc.

\section{Limitation and Future Work}

Since this paper only selects the Web of Science Core Collection as the basic database, and the research scope is limited to the peer-reviewed English journal articles related to the search terms, the coverage of selected literature is incomplete. At the same time, in the process of citation analysis, co-authorship analysis, bibliographic coupling analysis and keyword co-occurrence analysis, initial thresholds are set on the research objects. And some researches with novel topics but few publications are also kicked out of the research scope. Moreover, due to the time lag in the creation, publication, and citation of academic achievements, there should be a delay in the definition of academic hot topics in this paper. Bibliometrics analysis mainly uses the external feature information of the article to carry out structural analysis. It would be better to combine the method of meta-analysis to further analyze the specific data results of resource consumption from various analytical perspectives.

\section{CONCLUSION}

This study provides a review of current developments and hot topics about natural resource consumption and environment management based on Input-output research. Word frequency analysis, bibliographic coupling, and co-citation analysis are conducted to discover the evolution pattern of the research frontiers.

The results show that academic research in this field is increasing rapidly due to the ever-growing focus on sustainable development. While China is playing the role of the world's manufacturer, its demand for natural resources is soaring both at home and abroad. Although China started later, it has taken a global lead in citations and international cooperation. The distribution of high-level achievements in this field is relatively concentrated. Journals like Ecological Economics, Energy Policy, Journal of Cleaner Production, Science of the Total Environment, and Resources Conservation and Recycling are mainstream journals, from which is easier to track the academic frontiers. Depending on the topic, the literatures can be divided into two categories. One is the research on pollutant emissions related to fossil fuel's consumption. The other one is the research on natural resources, including energy, water, and land. With the development of the Multi-regional Input-output database, the research topic is gradually focusing on the sub-national and regional natural resources consumption accounting and management in the global supply chain. Methods such as LCA, MFA, SDA, SPA, network analysis, DEA, CGE and multiobjective optimization are also widely used in this field, which are combined with Input-output. The integration of these methods can obtain more comprehensive and accurate results for scientific decision-making.

\section{DATA AVAILABILITY STATEMENT}

The raw data supporting the conclusions of this article will be made available by the authors, without undue reservation.

\section{AUTHOR CONTRIBUTIONS}

SW: conceptualization, methodology, software, writing - original draft, and writing - review and editing. XT: conceptualization, funding acquisition, writing - review and editing, project administration, and supervision. BZ: conceptualization, software, and writing - review and editing. WW: software, writing original draft, and funding acquisition. All authors contributed to the article and approved the submitted version.

\section{FUNDING}

We appreciate the National Natural Science Foundation of China (71673297), Science Foundation of China University of Petroleum, Beijing (ZX20200109 and 2462020YXZZ041), and Soft Science Research Foundation of Zhejiang Province (2019C25G2020667) for sponsoring this research.

\section{SUPPLEMENTARY MATERIAL}

The Supplementary Material for this article can be found online at: https://www.frontiersin.org/articles/10.3389/fenrg.2021. 628321/full\#supplementary-material 


\section{REFERENCES}

Ayres, R. U., and Ayres, L. (2002). A Handbook of Industrial Ecology. UK: Edward Elgar Publishing.

Baiocchi, G., Minx, J., and Hubacek, K. (2010). The impact of social factors and consumer behavior on carbon dioxide emissions in the United Kingdom. J. Ind. Ecol. 14, 50-72. doi: 10.1111/j.1530-9290.2009.00216.x

Beylot, A., Ardente, F., Sala, S., and Zampori, L. (2020). Accounting for the dissipation of abiotic resources in LCA: status, key challenges and potential way forward. Resour. Conserv. Recycl. 157:104748. doi: 10.1016/j.resconrec.2020. 104748

Bleischwitz, R., Spataru, C., VanDeveer, S. D., Obersteiner, M., der Voet, E., Johnson, C., et al. (2018). Resource nexus perspectives towards the United Nations sustainable development goals. Nat. Sustainabil. 1, 737-743. doi: 10. 1038/s41893-018-0173-2

Boyack, K. W., and Klavans, R. (2010). Co-citation analysis, bibliographic coupling, and direct citation: which citation approach represents the research front most accurately? J. Am. Soc. Inform. Sci. Technol. 61, 2389-2404. doi: 10.1002/asi. 21419

Bruckner, M., Giljum, S., Lutz, C., and Wiebe, K. S. (2012). Materials embodied in international trade - global material extraction and consumption between 1995 and 2005. Global Environ. Change 22, 568-576. doi: 10.1016/j.gloenvcha.2012. 03.011

Chen, G. Q., and Chen, Z. M. (2010). Carbon emissions and resources use by Chinese economy 2007: a 135-sector inventory and input-output embodiment. Commun. Nonlinear Sci. Numer. Simul. 15, 3647-3732. doi: 10.1016/j.cnsns. 2009.12.024

Chen, G. Q., and Zhang, B. (2010). Greenhouse gas emissions in china 2007: inventory and input-output analysis. Energy Policy 38, 6180-6193. doi: 10.1016/ j.enpol.2010.06.004

Chen, Z. M., and Chen, G. Q. (2011). Embodied carbon dioxide emission at supranational scale: a coalition analysis for G7, BRIC, and the rest of the world. Energy Policy 39, 2899-2909. doi: 10.1016/j.enpol.2011.02.068

Chen, Z. M., Chen, G. Q., Zhou, J. B., Jiang, M. M., and Chen, B. (2010). Ecological input-output modeling for embodied resources and emissions in Chinese economy 2005. Commun. Nonlinear Sci. Numer. Simul. 15, 1942-1965. doi: 10.1016/j.cnsns.2009.08.001

Crawford, R. H. (2008). Validation of a hybrid life-cycle inventory analysis method. J. Environ. Manag. 88, 496-506. doi: 10.1016/j.jenvman.2007.03.024

Druckman, A., and Jackson, T. (2009). The carbon footprint of uk households 1990-2004: a socio-economically disaggregated, quasi-multi-regional inputoutput model. Ecol. Econ. 68, 2066-2077. doi: 10.1016/j.ecolecon.2009.01.013

Du, H., Li, B., Brown, M. A., Mao, G., Rameezdeen, R., and Chen, H. (2015). Expanding and shifting trends in carbon market research: a quantitative bibliometric study. J. Clean. Prod. 103, 104-111. doi: 10.1016/j.jclepro.2014. 05.094

Feng, C., Tang, X., Jin, Y., Guo, Y., and Zhang, X. (2019). Regional energy-water nexus based on structural path betweenness: a case study of Shanxi province, China. Energy Policy 127, 102-112. doi: 10.1016/j.enpol.2018.12.002

Fischer-Kowalski, M., Krausmann, F., Giljum, S., Lutter, S., Mayer, A., Bringezu, S., et al. (2011). Methodology and indicators of economy-wide material flow accounting. J. Ind. Ecol. 15, 855-876. doi: 10.1111/j.1530-9290.2011.00366.x

Genovese, A., Acquaye, A. A., Figueroa, A., and Koh, S. C. L. (2017). Sustainable supply chain management and the transition towards a circular economy: evidence and some applications. Omega 66, 344-357. doi: 10.1016/j.omega. 2015.05.015

Guan, D. B., Hubacek, K., Weber, C. L., Peters, G. P., and Reiner, D. M. (2008). The drivers of chinese CO2 emissions from 1980 to 2030. Global Environ. Change 18, 626-634. doi: 10.1016/j.gloenvcha.2008.08.001

Guan, D. B., Su, X., Zhang, Q., Peters, G. P., Liu, Z., Lei, Y., et al. (2014). The socioeconomic drivers of China's primary PM2.5 emissions. Environ. Res. Lett. 9:024010. doi: 10.1088/1748-9326/9/2/024010

Hanley, N., McGregor, P. G., Swales, J. K., and Turner, K. (2009). Do increases in energy efficiency improve environmental quality and sustainability? Ecol. Econ. 68, 692-709. doi: 10.1016/j.ecolecon.2008.06.004

Hawkins, J., Ma, C. B., Schilizzi, S., and Zhang, F. (2015). Promises and pitfalls in environmentally extended input-output analysis for China: a survey of the literature. Energy Econ. 48, 81-88. doi: 10.1016/j.eneco.2014.12.002
Hawkins, T., Hendrickson, C., and Matthews, H. S. (2007). "Uncertainty in the mixed-unit input-output life cycle assessment (MUIO-LCA) model of the US Economy," in Proceedings of the 16th International Input-Output Conference of the International Input-Output Association (IIOA), Istanbul, Turkey.

Hertwich, E. G., Hammitt, J. K., and Pease, W. S. (2000). A theoretical foundation for life-cycle assessment. J. Ind. Ecol. 4, 13-28.

Hoekstra, R., Edens, B., Zult, D., and Wilting, H. (2014). Reducing the variation of environmental footprint estimates based on multiregional input-output databases. Sustainabil. Account. Manag. Policy J. 5, 325-345. doi: 10.1108/ sampj-01-2014-0006

Hondo, H. (2005). Life cycle GHG emission analysis of power generation systems: Japanese case. Energy 30, 2042-2056. doi: 10.1016/j.energy.2004.07.020

Hong, J., Shen, Q., and Xue, F. (2016). A multi-regional structural path analysis of the energy supply chain in China's construction industry. Energy Policy 92, 56-68. doi: 10.1016/j.enpol.2016.01.017

Hu, X. F., Zhao, J., Zha, S. P., Lu, F., and Wang, X. F. (2015). An analysis of the evolution of topics and future trends in ecological security research. Acta Ecol. Sinica 35, 6934-6946.

International Resource Panel (2019). Global Resource Outlook 2019: Natural Resources for the Future We Want. Nairobi: United Nations Environment Programme.

Irwin, E. G., Isserman, A. M., Kilkenny, M., and Partridge, M. D. (2010). A century of research on rural development and regional issues. Am. J. Agric. Econ. 92, $522-553$.

Jin, Y., Behrens, P., Tukker, A., and Scherer, L. (2019). Water use of electricity technologies: a global meta-analysis. Renew. Sustainable Energy Rev. 115:109391. doi: 10.1016/j.rser.2019.109391

Jin, Y., Tang, X., Feng, C. Y., and Höök, M. (2017). Energy and water conservation synergy in China: 2007-2012. Resour. Conserv. Recycl. 127, 206-215. doi: 10. 1016/j.resconrec.2017.09.004

Kessler, M. M. (1963). Bibliographic coupling between scientific papers. Am. Documentation 14, 10-25. doi: 10.1002/asi.5090140103

Kondo, Y., Nakajima, K., Matsubae, K., and Nakamura, S. (2012). The anatomy of capital stock: input-output material flow analysis (MFA) of the material composition of physical stocks and its evolution over time. Revue de Métallurgie 109, 293-298. doi: 10.1051/metal/2012022

Kyoto Protocol (2005). United Nations Framework Convention on Climate Change. Kyoto: United Nation.

Lenzeiy, M., Kanemoto, K., Moran, D., and Geschke, A. (2012). Mapping the structure of the world economy. Environ. Ence Technol. 46:8374.

Lenzen, M. (2008). Errors in conventional and input-output- based life- cycle inventories. J. Ind. Ecol. 4, 127-148. doi: 10.1162/10881980052541981

Lenzen, M., and Murray, S. A. (2001). A modified ecological footprint method and its application to australia. Ecol. Econ. 37, 229-255. doi: 10.1016/s09218009(00)00275-5

Lenzen, M., Moran, D., Kanemoto, K., Foran, B., Lobefaro, L., and Geschke, A. (2012). International trade drives biodiversity threats in developing nations. Nature 486, 109-112. doi: 10.1038/nature11145

Leontief, W. (1970). Environmental repercussions and the economic structure: an input-output approach: a reply. Rev. Econ. Stats. 56, 109-110. doi: 10.2307/ 1927535

Li, F., Ye, Z., Xiao, X., Xu, J., and Liu, G. (2020). Material stocks and flows of power infrastructure development in China. Resour. Conserv. Recycl. 160:104906. doi: 10.1016/j.resconrec.2020.104906

Liang, S., Wang, Y., Zhang, T., and Yang, Z. (2017). Structural analysis of material flows in China based on physical and monetary input-output models. J. Clean. Prod. 158, 209-217. doi: 10.1016/j.jclepro.2017.04.171

Liang, S., Xu, M., Liu, Z., Suh, S., and Zhang, T. (2013). Socioeconomic drivers of mercury emissions in China from 1992 to 2007. Environ. Sci. Technol. 47, 3234-3240. doi: 10.1021/es303728d

Lin, B., and Sun, C. (2010). Evaluating carbon dioxide emissions in international trade of china. Energy Policy 38, 613-621. doi: 10.1016/j.enpol.2009.10.014

Liu, L. C., Wu, G., Wang, J. N., and Wei, Y. M. (2011). China's carbon emissions from urban and rural households during 1992-2007. J. Clean. Prod. 19, 17541762. doi: 10.1016/j.jclepro.2011.06.011

Machado, G., Schaeffer, R., and Worrell, E. (2001). Energy and carbon embodied in the international trade of Brazil: an input-output approach. Ecol. Econ. 39, 409-424. doi: 10.1016/s0921-8009(01)00230-0 
Mallapaty, S. (2020). How China could be carbon neutral by mid-century. Nature 586, 482-483. doi: 10.1038/d41586-020-02927-9

Marshakova, I. V. (1973). A system of document connections based on references. Sci. Techn. Inform. Ser. VINITI 6, 3-8.

Mi, Z. F., Zhang, Y. K., Guan, D. B., Shan, Y. L., Liu, Z., Cong, R. G., et al. (2016). Consumption-based emission accounting for chinese cities. Appl. Energy 184, 1073-1081. doi: 10.1016/j.apenergy.2016.06.094

Munksgaard, J., Wier, M., Lenzen, M., and Dey, C. (2005). Using input-output analysis to measure the environmental pressure of consumption at different spatial levels. J. Ind. Ecol. 9, 169-185. doi: 10.1162/1088198054084699

Naessen, J., Holmberg, J., Wadeskog, A., and Nyman, M. (2007). Direct and indirect energy use and carbon emissions in the production phase of buildings: an input-output analysis. Energy 32, 1593-1602. doi: 10.1016/j.energy.2007.01.002

Pachauri, S., and Spreng, D. (2002). Direct and Indirect Energy Requirements of Households in India. Berlin: Springer.

Peters, G. P., Minx, J. C., Weber, C. L., and Edenhofer, O. (2011). Growth in emission transfers via international trade from 1990 to 2008. Proc. Natl. Acad. Sci. U.S.A. 108, 8903-8908. doi: 10.1073/pnas. 1006388108

Peters, G. P., Weber, C. L., Guan, D. B., and Hubacek, K. (2007). China's growing $\mathrm{CO} 2$ emissions - a race between increasing consumption and efficiency gains. Environ. Sci. Technol. 41, 5939-5944. doi: 10.1021/es070108f

Román-Collado, R., and Colinet, M. J. (2018). Is energy efficiency a driver or an inhibitor of energy consumption changes in Spain? two decomposition approaches. Energy Policy 115, 409-417. doi: 10.1016/j.enpol.2018. 01.026

Sleeswijk, A. W., Oers, L. F., Guinee, J. B., Struijs, J., and Huijbregts, M. A. J. (2008). Normalisation in product life cycle assessment: an LCA of the global and european economic systems in the year 2000. Ence Total Environ. 390, 227-240. doi: $10.1016 /$ j.scitotenv.2007.09.040

Small, H. (1973). Co-citation in the scientific literature: a new measure of the relationship between two documents. J. Am. Soc. Inform. Sci. 24, 265-269. doi: 10.1002/asi.4630240406

$\mathrm{Su}, \mathrm{B}$. , and Ang, B. W. (2013). Input-output analysis of $\mathrm{CO} 2$ emissions embodied in trade: competitive versus non-competitive imports. Energy Policy 56, 83-87. doi: 10.1016/j.enpol.2013.01.041

$\mathrm{Su}, \mathrm{B}$., and Ang, B. W. (2014). Input-output analysis of $\mathrm{CO} 2$ emissions embodied in trade: a multi-region model for china. Appl. Energy 114, 377-384. doi: 10.1016/j.apenergy.2013.09.036

Suh, S., Lenzen, M., Treloar, G. J., Hondo, H., Horvath, A., Huppes, G., et al. (2004). System boundary selection in life-cycle inventories using hybrid approaches. Environ. Sci. Technol. 38, 657-664. doi: 10.1021/es0263745

Tang, X., Jin, Y., Feng, C. Y., and McLellan, B. C. (2018). Optimizing the energy and water conservation synergy in China: 2007-2012. J. Clean. Prod. 175, 8-17. doi: 10.1016/j.jclepro.2017.11.100

Thomas, B. A., and Azevedo, I. L. (2013a). Estimating direct and indirect rebound effects for U.S. households with input-output analysis Part 1: theoretical framework. Ecol. Econo. 86, 199-210. doi: 10.1016/j.ecolecon.2012.12.003

Thomas, B. A., and Azevedo, I. L. (2013b). Estimating direct and indirect rebound effects for u.s. households with input-output analysis. part 2: simulation. Ecol. Econ. 86, 199-210.

Tukker, A., and Jansen, B. (2006). Environmental impacts of productos. a detailed review of studies. J. Ind. Ecol. 10, 159-182. doi: 10.1162/jiec.2006.10. 3.159

Tukker, A., de Koning, A., Owen, A., Lutter, S., Bruckner, M., Giljum, S., et al. (2018). Towards robust, authoritative assessments of environmental impacts embodied in trade: Current State and Recommendations. J. Ind. Ecol. 22, 585-598. doi: $10.1111 /$ jiec. 12716

United Nation-UN (2015). United Nations-Resolution Adopted by the General Assembly on 25 September 2015-Transforming our world: the 2030 Agenda for Sustainable Development. New York, NY: United Nation.

Van Der Veen, A. V. D., and Logtmeijer, C. (2005). Economic hotspots: visualizing vulnerability to flooding. Nat. Hazards 36, 65-80. doi: 10.1007/s11069-004$4542-\mathrm{y}$

Van Eck, N. J., and Waltman, L. (2010). Software survey: VOSviewer, a computer program for bibliometric mapping. Scientometrics $84,523-538$. doi: $10.1007 /$ s11192-009-0146-3
Van Eck, N. J., and Waltman, L. (2014). Visualizing Bibliometric Networks. New York: Springer International Publishing.

Van Raan, A. F. J. (2005). For your citations only? hot topics in bibliometric analysis. Measurement 3, 50-62. doi: 10.1207/s15366359mea0301_7

Wang, S. Y., Tang, X., Wang, J. L., Zhang, B. S., Sun, W. M., and Höök, M. (2021). Environmental impacts from conventional and shale gas and oil development in China considering regional differences and well depth. Resour. Conserv. Recycl. $167: 105360$.

Wang, Z. H., and Yang, Y. (2015). Features and influencing factors of carbon emissions indicators in the perspective of residential consumption: evidence from Beijing, China. Ecol. Indic. 61, 634-645. doi: 10.1016/j.ecolind.2015.10.015

Weber, C. L. (2008). "Uncertainties in constructing environmental multiregional input-output models," in Proceedings of the Conference on International InputOutput Meeting on Managing the Environment, Seville, Spain. Available online at: http://www.upo.es/econ/IIOMME08/index.php

Weber, C. L., and Matthews, H. S. (2008). Quantifying the global and distributional aspects of american household carbon footprint. Ecol. Econ. 66, 379-391. doi: 10.1016/j.ecolecon.2007.09.021

Weinzettel, J., Hertwich, E. G., Peters, G. P., Steen-Olsen, K., and Galli, A. (2013). Affluence drives the global displacement of land use. Global Environ. Change 23, 433-438. doi: 10.1016/j.gloenvcha.2012.12.010

Wiebe, K. S., Bruckner, M., Giljum, S., Lutz, C., and Polzin, C. (2012). Carbon and materials embodied in the international trade of emerging economies. J. Ind. Ecol. 16, 636-646. doi: 10.1111/j.1530-9290.2012.00504.x

Wiedmann, T. (2009). A review of recent multi-region input-output models used for consumption-based emission and resource accounting. Ecol. Econ. 69, 211-222. doi: 10.1016/j.ecolecon.2009.08.026

Wiedmann, T., and Lenzen, M. (2018). Environmental and social footprints of international trade. Nat. Geosci. 11, 314-321. doi: 10.1038/s41561-018-0113-9

Wiedmann, T., Schandl, H., Lenzen, M., Moran, D., Suh, S., West, J., et al. (2013). The material footprint of nations. Proc. Natl. Acad. Sci. U.S.A. 112, 6271-6276.

Wiedmann, T., Wilting, H. C., Lenzen, M., Lutter, S., and Palm, V. (2011). Quo Vadis MRIO? methodological, data and institutional requirements for multi-region input-output analysis. Ecol. Econ. 70, 1937-1945. doi: 10.1016/ j.ecolecon.2011.06.014

Wood, R., Stadler, K., Bulavskaya, T., Lutter, S., Giljum, S., de Koning, A., et al. (2015). Global sustainability accounting-developing exiobase for multiregional footprint analysis. Sustainability 7, 138-163. doi: 10.3390/su7010138

Xia, E. J., Wang, S. J., and Wang, J. P. (2017). An analysis of the research status and development trend of crowdfunding based on the theory of scientific knowledge map. Sci. Res. Manag. 38, 1-8.

Xie, F. S., Cheng, H., and Li, A. (2014). An analysis of global climate control from the viewpoint of political economy. China Acad. J. 6, 205-206.

Xie, Y. L., Zhang, B. B., and Huang, G. D. (2018). Evolution of the Scientific Literature on input-output analysis: a bibliometric analysis of 1990-2017. Sustainability 10:3135. doi: 10.3390/su10093135

Xinhuanet.com (2020). Address at the 75th General Debate of the United Nations General Assembly. Available online at: http://www.xinhuanet.com/2020-09/22/ c_1126527652.htm (accessed 11 November 2020)

Zhang, P., and Peeta, S. (2011). A generalized modeling framework to analyze interdependencies among infrastructure systems. Transp. Res. B Methodol. 45, 553-579. doi: 10.1016/j.trb.2010.10.001

Zhong, S. Z., Geng, Y., Liu, W. J., Gao, C. X., and Chen, W. (2016). A bibliometric review on natural resource accounting during 1995-2014. J. Clean. Prod. 139, 122-132. doi: 10.1016/j.jclepro.2016.08.039

Conflict of Interest: The authors declare that the research was conducted in the absence of any commercial or financial relationships that could be construed as a potential conflict of interest.

Copyright (๑) 2021 Wang, Tang, Zhang and Wang. This is an open-access article distributed under the terms of the Creative Commons Attribution License (CC BY). The use, distribution or reproduction in other forums is permitted, provided the original author(s) and the copyright owner(s) are credited and that the original publication in this journal is cited, in accordance with accepted academic practice. No use, distribution or reproduction is permitted which does not comply with these terms. 